\title{
A Relaxed Matrix Inversion Method for Retrieving Water Constituent Concentrations in Case II Waters: the Case of Lake Kasumigaura, Japan
}

\author{
Wei Yang $^{1,2}$, Bunkei Matsushita ${ }^{2 *}$, Jin Chen ${ }^{1}$, Takehiko Fukushima ${ }^{2}$
}

${ }^{1}$ State key laboratory of earth surface processes and resource ecology, Beijing Normal University, Beijing, 100875, China

E-mail: yangwei1022@gmail.com, chenjin@ires.cn

${ }^{2}$ Graduate School of Life and Environmental Sciences, University of Tsukuba

1-1-1 Tennoudai, Tsukuba, Ibaraki, 305-8572, Japan

E-mails: mbunkei@sakura.cc.tsukuba.ac.jp,

fukusima@sakura.cc.tsukuba.ac.jp

Submittal date: 2010-9-2

*Corresponding Author

E-mail: mbunkei@sakura.cc.tsukuba.ac.jp 


\section{A Relaxed Matrix Inversion Method for Retrieving Water Constituent Concentrations in Case II Waters: the Case of Lake Kasumigaura, Japan}

\section{Abstract}

The matrix inversion method (MIM) is an effective algorithm for estimating water constituent concentrations in case II waters. To apply this method, appropriate and accurate specific inherent optical properties (SIOPs) for each constituent in water are essential. However, many routine observations of lake water quality do not in fact provide SIOPs, thus limiting the application of the MIM. In this study, an alternative MIM method based on linear matrix inversion theory was proposed to relax the requirement of SIOPs measurement. For this, so-called ESIOPs (Estimated SIOPs) were first derived by an unusual application of MIM based on adequate calibration samples; then the water constituent concentrations for the whole study area were retrieved by the standard application of MIM based on the derived ESIOPs. For each calibration sample, measurement of the reflectance spectrum and corresponding water constituent concentrations, which can be obtained from periodical satellite data and routine field surveys, is required. The performance of the proposed method was evaluated using the simulation data from Hydrolight and three MEdium Resolution Imaging Spectrometer Instrument (MERIS) images. The results showed that this method yielded satisfactory estimations of the water constituent concentrations for the noise-contaminated simulation datasets. For MERIS data in our study area (Lake Kasumigaura, Japan), the average bias (mean normalized bias, or MNB) and relative random uncertainty (normalized root mean square error, or NRMS) were in the range of $-11.2 \%$ to $3.4 \%$ and $4.8 \%$ to $29.7 \%$ for each water constituent 
concentration. These findings imply that the algorithm proposed in this study is theoretically reasonable and practically applicable.

Index terms - Matrix inversion method, case II waters, estimated SIOPs, routine observations

\section{Introduction}

Water quality monitoring is a critical requirement for water resource management, which is important for supporting sustainable development [1]. Remote sensing techniques are very useful for such monitoring, in terms of being able to cover large spatial areas at very frequent intervals. From the remote sensing perspective, global waters can be generally divided into two classes: case I and case II waters [2]. Case I waters are those dominated by phytoplankton (e.g. open oceans), whereas case II waters are waters influenced not only by phytoplankton and related particles but also by other substances (notably inorganic particles in suspension and yellow substances) that vary independently of phytoplankton (e.g., some coastal and inland waters) [3]. The remote sensing of case II waters has been far less successful than that of case I waters, mainly due to the complex interactions among optically active substances in the former [4-6].

Significant efforts have been made to improve the accuracy of the estimation of water quality for case II waters. These efforts include the use of derivative values of reflectance spectra [7], examination of the band ratio of near-infrared reflectance and red reflectance $[4,6,8]$, the conceptual three-band model [9], the matrix inversion method (MIM) [10, 11], the use of spectral 
mixture analysis techniques[12-14], the use of non-linear optimization techniques based on a radiative transfer model $[15,16]$, and others.

Among these approaches, the MIM, which is based on a direct inversion of a bio-optical model, is simple and effective. Since it was first proposed by Hoge and Lyon [10], the MIM shows great potential for retrieving water constituent concentrations in case II waters with high estimation accuracy. For example, Hoogenboom et al. [11] successfully applied it in airborne hyperspectral data. Brando and Dekker [17] validated the effectiveness of the MIM with the space-borne hyperspectral data known as EO-1/Hyperion data. Giardino et al. [18] successfully applied MIM to the EO-1/Hyperion data to assess the water quality in Lake Garda, Italy, with the satisfactory result that the correlation coefficients between the in situ collected and Hyperion-derived concentrations were larger than 0.75 .

The key factor in the successful application of the MIM is whether accurate and appropriate specific inherent optical properties (SIOPs) can be obtained for each water component. However, in two types of circumstances, the SIOPs are unavailable for many applications. First, the instruments for measuring the SIOPs such as AC-9 and Hydroscat may not be available to a particular research group. Second, in some cases a post-session analysis needs to be carried out, but the SIOPs were not collected at those times. Moreover, long-term variability of the SIOPs in a lake may occur. For example, the SIOPs of Lake Geneva, one of the largest lakes in Western Europe, significantly shifted during the period from 2003 to 2007 [19]. The errors included in the SIOPs would significantly decrease the accuracy of the MIM [20]. Therefore, even if the SIOPs data have begun to be collected in water areas, it is still questionable whether the present-day SIOPs data can be used to perform 
MIM for past decades. As a result, the usefulness of the MIM is greatly limited in many applications where SIOP measurements are not available, especially in the case of post-session studies.

By contrast, concentrations of water constituents such as chlorophyll-a, total suspended solids (TSS), and dissolved organic carbon (DOC) are routine measurements for many lakes. In the case of Lake Kasumigaura (the second largest lake in Japan), these data have been routinely collected by the National Institute for Environmental Sciences (NIES) every month at 10 sites since the 1970s. Meanwhile, satellite sensors such as Coastal Zone Color Scanner (CZCS), Sea-viewing Wide Field-of-view Sensor (SeaWiFS), MODerate resolution Imaging Spectroradiometer (MODIS), and MEdium Resolution Imaging Spectrometer Instrument (MERIS) have provided remote-sensing reflectance every day or every 3 days since 1978. Combining these routine measurements and satellite data can produce a long-term understanding of distributions and trends of water quality parameters in the past. This would be of great help for effective and sustainable management of the lake’s water.

The objective of this study was to propose an alternative version of the MIM. The proposed method requires only routine measurements and satellite data as inputs, and does not require the measurement of SIOPs for each water component. The performance of the proposed method was first evaluated by a sensitivity analysis based on a set of simulation data; the applicability of the proposed method was then verified in Lake Kasumigaura using three MERIS images and datasets from in situ monitoring. 


\section{Methods and Materials}

\section{A. Bio-optical model}

According to Gordon et al. [21], the remote-sensing reflectance just beneath the water surface is expressed as:

$$
r_{\mathrm{rs}}(\lambda)=f \frac{b_{\mathrm{b}}(\lambda)}{a(\lambda)+b_{\mathrm{b}}(\lambda)}
$$

with

$$
f=g_{0}+g_{1} \frac{b_{\mathrm{b}}(\lambda)}{a(\lambda)+b_{\mathrm{b}}(\lambda)}
$$

where $a(\lambda)$ and $b_{\mathrm{b}}(\lambda)$ are the spectral total absorption and backscattering coefficients, respectively; $f$ is a proportional factor; and $g_{0}$ and $g_{1}$ are constants.

The spectral total absorption coefficient is usually expressed as the sum of the constituents’ absorption coefficients, as follows:

$$
a(\lambda)=a_{\mathrm{w}}(\lambda)+[\mathrm{Chl}-\mathrm{a}] a_{\mathrm{ph}}^{*}(\lambda)+[\mathrm{TR}] a_{\mathrm{tr}}^{*}(\lambda)+[\mathrm{CDOM}] a_{\mathrm{CDOM}}^{*}(\lambda)
$$

where [Chl-a] and [TR] denote the concentrations of chlorophyll-a and tripton, respectively, and [CDOM] denotes the absorption of CDOM at $440 \mathrm{~nm}$. The variable $a_{\mathrm{w}}(\lambda)$ is the absorption coefficient of pure water; $a_{\mathrm{ph}}^{*}(\lambda), a_{\mathrm{tr}}^{*}(\lambda)$, and $a_{\mathrm{CDOM}}^{*}(\lambda)$ are the specific absorption coefficients of phytoplankton, tripton and CDOM, respectively.

The spectral total backscattering coefficient is expressed as the sum of the backscattering coefficients for each constituent in water except for CDOM, as follows:

$$
b_{\mathrm{b}}(\lambda)=b_{\mathrm{b}, \mathrm{w}}(\lambda)+[\mathrm{Chl}-\mathrm{a}] b_{\mathrm{b}, \mathrm{ph}}^{*}(\lambda)+[\mathrm{TR}] b_{\mathrm{b}, \mathrm{tr}}^{*}(\lambda)
$$

where $b_{\mathrm{b}, \mathrm{w}}(\lambda)$ is the backscattering coefficient of pure water, and $b_{\mathrm{b}, \mathrm{ph}}^{*}(\lambda)$ and $b_{\mathrm{b}, \mathrm{tr}}(\lambda)$ are the specific backscattering coefficients of phytoplankton and tripton, respectively. 
Austin [22] proposed the factor of 0.544 for relating the radiance just above the surface to the radiance just beneath the surface. Thus, the remote-sensing reflectance just above the water surface is as follows:

$$
R_{\mathrm{rs}}(\lambda)=0.544 r_{\mathrm{rs}}(\lambda)=0.544 f \frac{b_{\mathrm{b}}(\lambda)}{a(\lambda)+b_{\mathrm{b}}(\lambda)}
$$

\section{B. Matrix Inversion Method (MIM)}

The MIM was developed based on a direct inversion of the bio-optical model [11, 17]. Eq. (1)

can be rewritten by substituting $a(\lambda)$ and $b_{\mathrm{b}}(\lambda)$ with Eqs. (3) and (4), respectively, as:

$$
\frac{r_{\mathrm{rs}}(\lambda)}{f}=\frac{[\mathrm{Chl}-\mathrm{a}] b_{\mathrm{b}, \mathrm{ph}}^{*}(\lambda)+[\mathrm{TR}] b_{\mathrm{b}, \mathrm{r}}^{*}(\lambda)+b_{\mathrm{b}, \mathrm{w}}(\lambda)}{[\mathrm{Chl}-\mathrm{a}]\left(a_{\mathrm{ph}}^{*}(\lambda)+b_{\mathrm{b}, \mathrm{ph}}^{*}(\lambda)\right)+[\mathrm{TR}]\left(a_{\mathrm{tr}}^{*}(\lambda)+b_{\mathrm{b}, \mathrm{rt}}^{*}(\lambda)\right)+[\mathrm{CDOM}] a_{\mathrm{CDOM}}^{*}(\lambda)+a_{\mathrm{w}}(\lambda)+b_{\mathrm{b}, \mathrm{w}}(\lambda)}
$$

The inherent and apparent optical properties are dependent on wavelength, but the water constituent concentrations are not. Therefore, if there are $M$ bands available, this equation can be rewritten as a set of $M$ equations, where each equation has the form:

$$
\begin{aligned}
& \text { [Chl-a] } \cdot\left(a_{\mathrm{ph}}^{*}\left(\lambda_{j}\right) \frac{r_{\mathrm{rs}}\left(\lambda_{j}\right)}{f}-b_{\mathrm{b}, \mathrm{ph}}^{*}\left(\lambda_{j}\right)\left(1-\frac{r_{\mathrm{rs}}\left(\lambda_{j}\right)}{f}\right)\right) \\
& +[\mathrm{TR}] \cdot\left(a_{\mathrm{tr}}^{*}\left(\lambda_{j}\right) \frac{r_{\mathrm{rs}}\left(\lambda_{j}\right)}{f}-b_{\mathrm{b}, \mathrm{r}}^{*}\left(\lambda_{j}\right)\left(1-\frac{r_{\mathrm{rs}}\left(\lambda_{j}\right)}{f}\right)\right) \\
& +[\mathrm{CDOM}] \cdot a_{\mathrm{CDOM}}^{*}\left(\lambda_{j}\right) \frac{r_{\mathrm{rs}}\left(\lambda_{j}\right)}{f} \\
& =b_{b, w}\left(\lambda_{j}\right)\left(1-\frac{r_{\mathrm{rs}}\left(\lambda_{j}\right)}{f}\right)-a_{w}\left(\lambda_{j}\right) \frac{r_{\mathrm{rs}}\left(\lambda_{j}\right)}{f}
\end{aligned}
$$

where the subscript $j(j=1,2, \ldots, M)$ denotes the $j$-th band for SIOPs and the remote-sensing reflectance. Eq. (7) can be represented in a more concise form using matrix notation: 


$$
\begin{aligned}
& {\left[\begin{array}{cc}
a_{\mathrm{ph}}^{*}\left(\lambda_{1}\right) \frac{r_{\mathrm{rs}}\left(\lambda_{1}\right)}{f}-b_{\mathrm{b}, \mathrm{ph}}^{*}\left(\lambda_{1}\right)\left(1-\frac{r_{\mathrm{rs}}\left(\lambda_{1}\right)}{f}\right) & \ldots . . \\
\vdots & \\
a_{\mathrm{ph}}^{*}\left(\lambda_{M}\right) \frac{r_{\mathrm{rs}}\left(\lambda_{M}\right)}{f}-b_{\mathrm{b}, \mathrm{ph}}^{*}\left(\lambda_{M}\right)\left(1-\frac{r_{\mathrm{rs}}\left(\lambda_{M}\right)}{f}\right) & \ldots . . .
\end{array}\right]_{M \times 3}\left[\begin{array}{c}
{[\mathrm{Chl}-\mathrm{a}]} \\
{[\mathrm{TR}]} \\
{[\mathrm{CDOM}]}
\end{array}\right]_{3 \times 1}} \\
& =\left[\begin{array}{c}
b_{b, w}\left(\lambda_{1}\right)\left(1-\frac{r_{\mathrm{rs}}\left(\lambda_{1}\right)}{f}\right)-a_{w}\left(\lambda_{1}\right) \frac{r_{\mathrm{rs}}\left(\lambda_{1}\right)}{f} \\
\vdots \\
b_{b, w}\left(\lambda_{M}\right)\left(1-\frac{r_{\mathrm{rs}}\left(\lambda_{M}\right)}{f}\right)-a_{w}\left(\lambda_{M}\right) \frac{r_{\mathrm{rs}}\left(\lambda_{M}\right)}{f}
\end{array}\right]_{M \times 1}
\end{aligned}
$$

There are three constituents (i.e. phytoplankton, tripton, and CDOM) of case II waters; thus, we need at least three bands to solve the above equations. When $M$ equals 3 , we can directly calculate the concentrations using the analytical solution of the linear system; when $M$ is greater than 3 , we can obtain the concentrations using the least square method. From Eq. (8), it is obvious that the SIOPs for each constituent should be known before MIM can be used.

\section{Development of a new MIM-based method without the SIOPs requirement}

To extend the application of MIM to cases in which appropriate SIOPs are unavailable, we propose a new MIM-based method, hereafter called the Relaxed Matrix Inversion Method (RMIM) because the SIOP requirements of the original MIM are relaxed.

In the original MIM, the unknown variables are the water constituent concentrations (i.e. [Chl-a], [TR], and [CDOM] in Eq. (8)), while the SIOPs are known in advance. Similarly, if we know the water constituent concentrations in advance, we can use linear matrix inversion theory to estimate the SIOPs. In such a case, Eq. (6) can be rewritten as: 


$$
\begin{aligned}
& a_{\mathrm{ph}}^{*}(\lambda) \cdot[\mathrm{Chl}-\mathrm{a}] \frac{r_{\mathrm{rs}}(\lambda)}{f}+a_{\mathrm{tr}}^{*}(\lambda) \cdot[\mathrm{TR}] \frac{r_{\mathrm{rs}}(\lambda)}{f}+a_{\mathrm{CDOM}}^{*}(\lambda) \cdot[\mathrm{CDOM}] \frac{r_{\mathrm{rs}}(\lambda)}{f}+a_{\mathrm{w}}(\lambda) \cdot \frac{r_{\mathrm{rs}}(\lambda)}{f} \\
& +b_{\mathrm{b}, \mathrm{ph}}^{*}(\lambda) \cdot[\mathrm{Chl}-\mathrm{a}]\left(\frac{r_{\mathrm{rs}}(\lambda)}{f}-1\right)+b_{\mathrm{b}, \mathrm{tr}}^{*}(\lambda) \cdot[\mathrm{TR}]\left(\frac{r_{\mathrm{rs}}(\lambda)}{f}-1\right)+b_{\mathrm{b}, \mathrm{w}}(\lambda) \cdot\left(\frac{r_{\mathrm{rs}}(\lambda)}{f}-1\right)=0
\end{aligned}
$$

The $a_{\mathrm{w}}(\lambda)$ and $b_{\mathrm{b}, \mathrm{w}}(\lambda)$ are absorption and backscattering coefficients of pure water, which can be taken from [23-25]. Therefore, if we have $N$ water samples and the $i$-th water sample $(i=1,2, \ldots, N)$ contains concentrations of $[\mathrm{Chl}-\mathrm{a}]_{i},[\mathrm{TR}]_{i}$, and $[\mathrm{CDOM}]_{i}$, and possesses the corresponding remote-sensing reflectance of $r_{\mathrm{r}, i}\left(\lambda_{j}\right)$ at band $\lambda_{j}(j=1,2, \ldots, M)$, then Eq. (9) can be rewritten as:

$$
\begin{aligned}
& a_{\mathrm{ph}}^{*}\left(\lambda_{j}\right) \cdot[\mathrm{Chl}-\mathrm{a}]_{i} \frac{r_{\mathrm{r}, i}\left(\lambda_{j}\right)}{f}+a_{\mathrm{tr}}^{*}\left(\lambda_{j}\right) \cdot[\mathrm{TRR}]_{i} \frac{r_{\mathrm{rs}, i}\left(\lambda_{j}\right)}{f}+a_{\mathrm{CDOM}}^{*}\left(\lambda_{j}\right) \cdot[\mathrm{CDOM}]_{i} \frac{r_{\mathrm{rs}, i}\left(\lambda_{j}\right)}{f} \\
& +b_{\mathrm{b}, \mathrm{hh}}^{*}\left(\lambda_{j}\right) \cdot[\mathrm{Chl}-\mathrm{a}]_{i}\left(\frac{r_{\mathrm{rs}, i}\left(\lambda_{j}\right)}{f}-1\right)+b_{\mathrm{b}, \mathrm{rr}}^{*}\left(\lambda_{j}\right) \cdot[\mathrm{TR}]_{i}\left(\frac{r_{\mathrm{r}, i}\left(\lambda_{j}\right)}{f}-1\right) \\
& \quad=b_{\mathrm{b}, \mathrm{w}}\left(\lambda_{j}\right)\left(1-\frac{r_{\mathrm{rs}, i}\left(\lambda_{j}\right)}{f}\right)-a_{\mathrm{w}}\left(\lambda_{j}\right) \frac{r_{\mathrm{rs}, i}\left(\lambda_{j}\right)}{f}
\end{aligned}
$$

Using matrix notation, Eq. (10) can be rewritten as follows:

$$
\left[\begin{array}{cc}
{[\mathrm{Chl}-\mathrm{a}]_{1} \frac{r_{\mathrm{r}, 1}\left(\lambda_{j}\right)}{f}} & \ldots . . . \\
\ldots & \\
{[\mathrm{Chl}-\mathrm{a}]_{N} \frac{r_{\mathrm{rs}, N}\left(\lambda_{j}\right)}{f}} & \cdots . . .
\end{array}\right]_{N \times 5}\left[\begin{array}{l}
a_{\mathrm{ph}}^{*}\left(\lambda_{j}\right) \\
a_{\mathrm{tr}}^{*}\left(\lambda_{j}\right) \\
a_{\mathrm{CDOM}}^{*}\left(\lambda_{j}\right) \\
b_{\mathrm{b}, \mathrm{th}}^{*}\left(\lambda_{j}\right)
\end{array}\right]_{5 \times 1}^{*}\left(\begin{array}{c}
b_{\mathrm{b}, \mathrm{w}}\left(\lambda_{j}\right)\left(1-\frac{r_{\mathrm{rs}, 1}\left(\lambda_{j}\right)}{f}\right)-a_{\mathrm{w}}\left(\lambda_{j}\right) \frac{r_{\mathrm{r}, 1}\left(\lambda_{j}\right)}{f} \\
\vdots \\
b_{\mathrm{b}, \mathrm{w}}\left(\lambda_{j}\right)\left(1-\frac{r_{\mathrm{r}, N}\left(\lambda_{j}\right)}{f}\right)-a_{\mathrm{w}}\left(\lambda_{j}\right) \frac{r_{\mathrm{r}, N}\left(\lambda_{j}\right)}{f}
\end{array}\right]_{N \times 1}
$$

It can be seen that there are five unknown variables (i.e. $a_{\mathrm{ph}}^{*}\left(\lambda_{j}\right), a_{\mathrm{tr}}^{*}\left(\lambda_{j}\right), a_{\mathrm{CDOM}}^{*}\left(\lambda_{j}\right), b_{\mathrm{b}, \mathrm{hh}}^{*}\left(\lambda_{j}\right)$ and $b_{\mathrm{b}, \mathrm{r}}^{*}\left(\lambda_{j}\right)$, called "Estimated SIOPs", or ESIOPs, to differentiate them from measured SIOPs). Therefore, we need at least five water samples to obtain the ESIOPs. If we use remote-sensing reflectance at a different band to substitute for $\mathrm{r}_{\mathrm{rs}, 1}\left(\lambda_{j}\right), \mathrm{r}_{\mathrm{rs}, 2}\left(\lambda_{j}\right), \ldots \mathrm{r}_{\mathrm{rs}, N}\left(\lambda_{j}\right)$ in Eq. (11), then we can obtain the ESIOPs at the corresponding band.

After the spectra of ESIOPs were derived, the water constituent concentrations for other water areas can be retrieved identically as the original MIM (i.e., Eq. (8)). 


\section{Sensitivity analysis}

To evaluate the performance of the RMIM, a sensitivity analysis was carried out based on three basic datasets. The first basic dataset contained a set of SIOPs, which was obtained from Brando and Dekker [17] and is hereafter called the "SIOPs dataset". The second basic dataset contained 100 combinations of water constituent concentrations, which were randomly varied with uniform distribution in the ranges of $0-20 \mathrm{mg} \mathrm{m}^{-3}$ for [Chl-a], 0-25 $\mathrm{g} \mathrm{m}^{-3}$ for [TR], and 0-0.5 $\mathrm{m}^{-1}$ for [CDOM], respectively (hereafter, the "concentration dataset”). These ranges were determined according to the maximum values of [Chl-a], [TR], and [CDOM] presented in Brando and Dekker [17]. The third basic dataset contained 100 noise-free remote-sensing reflectance spectra, which were generated using the Hydrolight numerical simulation code based on the IOPs derived from the first and second datasets by using equations 3 and 4 [26] (hereafter, the "reflectance dataset”). Parameters for Hydrolight simulation are summarized in Table 1. The reflectance dataset was separated into two groups: one was used to calculate the ESIOPs (Fig. 1-a); the other was used to assess the accuracy of RMIM (Fig. 1-b). Ten reflectance spectra (Fig. 1-a) were randomly selected from reflectance dataset to derive the ESIOPs from 460 to $740 \mathrm{~nm}$ at 10-nm intervals (Eq. 11), because there are 10 sampling sites available every month in the Lake Kasumigaura database [27]. Consequently, the other 90 reflectance spectra (Fig. 1-b) were used to estimate water constituent concentrations based on the obtained ESIOPs (Eq. 13).

The sensitivity analysis performed in this paper proceeded as follows:

1. Adding noise to the reflectance dataset. To simulate satellite remote-sensing reflectance spectra, two aspects of noise were considered in the sensitivity analysis. First, a white Gaussian noise 
was added to each band of the spectrum to reach a signal-to-noise (SNR) of 150:1. This corresponded to noise coming from imperfections of satellite sensors such as thermal effects, and was generally spectrally uncorrelated. Second, a spectrally correlated noise was also added to each band of the spectrum. This noise usually results from an imperfect atmospheric correction procedure, especially from the error of aerosol correction (refer to AC errors hereafter). Ruddick et al. [28] provided the values of AC errors for the wavelengths ranging from $412-865 \mathrm{~nm}$ for four combinations of atmosphere (clear or turbid) and water (clear or turbid). In this study, only the case of a clear atmosphere was considered. The simulated spectra were simply classified as clear water if $R_{\mathrm{rs}}(700)$ was less than $0.5 \%$; otherwise, as turbid water. The sensitivity analyses were made for percentages of AC errors from 0 to $100 \%$ with $10 \%$ interval. For each percentage of AC errors, 500 sets of white Gaussian noise were added to each band of the spectrum.

2. Adding noise to the concentration dataset. The RMIM requires water constituent concentrations to calculate the ESIOPs at first. Therefore, measurement errors in the concentrations should also be considered when evaluating the performance of RMIM. For this sensitivity analysis, the water constituent concentrations were added by relative errors of 5, 10, 15, 20, 25, 30, and $35 \%$, respectively. The sign of each relative error was randomly determined through Gaussian distribution. It should be noted that the noises were added only into the 10 combinations of constituent concentrations for ESIOPs calculation (corresponding to the reflectance spectra in Fig. 1-a); while the other 90 combinations for accuracy assessment (corresponding to the reflectance spectra in Fig. 1-b) were kept noise-free. For each relative error of concentration, 
500 sets of white Gaussian noise were added to each band of the spectrum.

3. Adding noise to the SIOPs dataset. The SIOPs for each constituent required by the MIM were also supplemented with noise for comparison analysis. The method for adding noise to the SIOPs dataset was same as that in the concentration dataset. Note that the absorption and scattering of pure water did not vary. A similar sensitivity analysis was also carried out based on the same basic datasets for the MIM for comparison.

Please insert Table 1 here

Please insert Fig. 1 here

\section{E. In situ and MERIS data collection}

To investigate the applicability of the RMIM, three field campaigns were carried out in Lake Kasumigaura, Japan, on September 3, 2007, on August 7, 2008 and on May 18, 2010.Water constituent concentrations for 61 sites were collected during the field campaign periods. A water sample collected at each site was taken to the laboratory to measure the water constituent concentrations. Chlorophyll-a was extracted using methanol (100\%) at $4^{\circ} \mathrm{C}$ for 24 hours under dark conditions. The optical density of the extracted chlorophyll-a was measured at four wavelengths (750, 663, 645 and $630 \mathrm{~nm}$ ), and the concentration was calculated according to the SCOR-UNESCO equations [29]. To obtain the concentration of tripton, the amount of total suspended solids (TSS) was divided into tripton and phytoplanktonic suspended solids. Based on the method of Gons et al. [30] and organic suspended solids data collected from Lake Kasumigaura, it can be assumed that a concentration of $1 \mathrm{mg} \mathrm{m}^{-3}$ chlorophyll-a is approximately equal to $0.12 \mathrm{~g} \mathrm{~m}^{-3}$ TSS. The absorption of 
CDOM was measured using a Shimadzu UV-1700 spectrophotometer with filtered water. The absorption of CDOM was measured using a Shimadzu UV-1700 spectrophotometer with filtered water.

Three full-resolution MERIS images (level-1b) covering Lake Kasumigaura were acquired on September 4, 2007, August 7, 2008, and May 18, 2010 (Fig. 2). Images were analyzed using BEAM 4.0 software (Brockmann Consult, Geesthacht, Germany). The images were first geo-registered. Then atmospheric correction was performed on the images using the SCAPE-M (Self-Contained Atmospheric Parameters Estimation for MERIS data) atmospheric processor proposed by Guanter et al. [31] after masking for land, cloud, and invalid reflectance. Evaluation of the atmospheric correction was performed by comparing satellite-generated spectra and in situ reflectance spectra, which were collected following so-called "Method 1" of Muller et al. [32]. Pixels contaminated by clouds and land were excluded; sampling sites located more than one pixel away from the bank were retained (Fig. 2). Sampling sites in August, 2008 were simply divided into two groups according to their spatial distribution throughout the lake. One group containing 11 sites (marked as red crosses in Fig. 2-a) was used as a calibration dataset to derive the ESIOPs, while the other sites (marked as pink circles in Fig. 2-a) were used to assess the estimation accuracy of retrieval methods. Sampling sites in May, 2010 were also divided into a calibration dataset (10 sites marked as red crosses in Fig. 2-b) and a validation dataset (11 sites marked as pink circles in Fig. 2-b) according to their spatial distribution. All the sites from September, 2007 (Fig. 2-c) were used for validation. 


\section{F. Accuracy assessment}

Three indices, namely the root mean square error (RMSE), mean normalized bias (MNB), and normalized root mean square error (NRMS) as suggested in Gitelson et al. [9], were used to assess the accuracies of the RMIM. These indices are defined as follows:

$$
\begin{aligned}
& \text { RMSE }=\sqrt{\frac{\sum_{i=1}^{N}\left(X_{\text {esti, }}-X_{\text {meas }, i}\right)^{2}}{N}} \\
& \text { MNB }=\operatorname{mean}\left(\varepsilon_{\mathrm{i}}\right) \% \\
& \text { NRMS }=\operatorname{stdev}\left(\varepsilon_{\mathrm{i}}\right) \%
\end{aligned}
$$

where $X_{\text {esti,i }}$ and $X_{\text {meas,i }}$ are the estimated and measured values, respectively, $N$ is the number of samples, and $\varepsilon_{\mathrm{i}}=100 \times\left(X_{\text {esti,i }}-X_{\text {meas, },}\right) / X_{\text {meas, }, i}$ is the percent difference between estimated and measured values. The MNB denotes the average bias in the estimation, while the NRMS denotes the relative random uncertainty of the results.

Please insert Fig. 2 here

\section{Results}

\section{A. Performances of MIM and RMIM for simulation data}

Before applying the MIM and RMIM, the proportional factor $f$ needed to be determined. For the original MIM, $f$ was obtained from Eq. (2) by determining the coefficients $g_{0}$ and $g_{1}$. Gordon et al. [21] presented that $g_{0} \approx 0.0949$ and $g_{1} \approx 0.0794$ for oceanic waters; while Lee et al. [33] suggested that a $g_{0}$ of 0.084 and $g_{1}$ of 0.17 were more appropriate for higher-scattering coastal waters. It was found that the values of $g_{0}$ and $g_{1}$ might vary with particle phase function [34], and were not known 
remotely. In this study, $g_{0}$ and $g_{1}$ were calculated as $g_{0} \approx 0.0855$ and $g_{1} \approx 0.1272$ from 300 Hydrolight simulations using regression analysis $\left(\mathrm{R}^{2}=0.998\right)$.

Since the RMIM does not require SIOPs, it is impossible to use Eq. (2) to determine the $f$ for the application of the RMIM. Accordingly, an alternative method was employed to estimate $f$ in the RMIM [35]:

$$
f=\frac{0.975-0.629 \mu_{0}}{Q}
$$

where $Q$ is an anisotropy factor for describing the upwelling light field; $\mu_{0}$ denotes the mean cosine of the zenith angle of the refracted photons, which is calculated according to the sampling time, locations, and solar zenith angle. In this study, an empirical equation $Q=2.38 / \mu_{0}$ developed for turbid inland waters under varying solar elevations was used [36].

Figure 3 shows the results of applying MIM and RMIM to the data with added white Gaussian noise and AC errors to the reflectance dataset. The mean and standard deviation (SD) of RMSE for retrieved water constituent concentrations were calculated. It could be seen that the SD (error bar in Fig. 3) of MIM and RMIM were low for the estimation of each water constituent concentration against each relative AC error, indicating that both methods are insensitive to instrument noise. For the effects of AC errors, the MIM shows sensitivity compared with the RMIM. The mean RMSE of the MIM for each water constituent concentration dramatically increased with the increase of AC errors. In contrast, the mean RMSE of the RMIM for each water constituent concentration shows a relatively stable pattern with the increase of AC errors. The RMIM yielded higher accuracy than the MIM for all levels of AC errors. Even if no noise due to the AC errors was added, neither method gave the exact concentrations, mainly because of the difference between the bio-optical model and 
Hydrolight software.

Figure 4 shows the results of adding relative errors to the concentration dataset or the SIOPs dataset. Since noise due to the imperfection of the sensor is always present in a measurement, the spectrally uncorrelated noise was still added to the reflectance dataset in this section. For the RMIM, it should be noted that the noises were only added to the water constituent concentrations which were used for calculating ESIOPs. Results show that the effects of inaccurate measurements of water constituent concentrations and SIOPs were larger than that of inaccurate spectra both for MIM and RMIM. For a relative AC error of 30\%, the mean RMSEs of [Chl-a], [TR], and [CDOM] for the RMIM were $2.1 \mathrm{mg} \mathrm{m}^{-3}, 0.4 \mathrm{~g} \mathrm{~m}^{-3}, 0.05 \mathrm{~m}^{-1}$, respectively (Fig. 3). By contrast, for the same relative error of concentration (30\%), the mean RMSEs were increased to $12.3 \mathrm{mg} \mathrm{m}^{-3}$ for [Chl-a], $8.6 \mathrm{~g} \mathrm{~m}^{-3}$ for [TR], and $0.5 \mathrm{~m}^{-1}$ for [CDOM], respectively (Fig. 4). The MIM showed results similar to those of the RMIM.

Please insert Fig. 3 here

Please insert Fig. 4 here

\section{B. Performance of the RMIM for MERIS data}

Before the MERIS data were used in the RMIM, atmospheric correction was carried out using the SCAPE-M. To show the effect of atmospheric correction, a $3 \times 3$ window was applied to the pixels corresponding to the sampling sites based on the GPS values. The mean atmospherically corrected reflectance of the $3 \times 3$ window was extracted and used for comparison with the in situ reflectance measured by the FieldSpec HandHeld (Analytical Spectral Devices, Inc., Boulder, CO, 
USA) for each MERIS band. Fig. 5 shows comparison results for the 2008 satellite image. It is evident that atmospheric correction by the SCAPE-M atmospheric processor is effective, with considerable agreement between the two remote-sensing reflectance spectra for the seven sites.

Band selection for the RMIM application was based on the typical spectral features of the water constituents and the accuracy of atmospheric correction for each band. Accordingly, the candidate bands should be (1) a blue band around $447 \mathrm{~nm}$ for the absorption of chlorophyll-a and CDOM, (2) a band at $550 \mathrm{~nm}$ representing the lowest influence of chlorophyll-a and CDOM, and (3) a band around $676 \mathrm{~nm}$ where chlorophyll-a has a red absorption maximum [17]. In addition, comparison of atmospherically corrected reflectance and in situ reflectance showed much higher accuracy for bands 4-9 (ranging from 510 to $708 \mathrm{~nm}$ ) than for the other bands (Fig. 5). Therefore, we selected MERIS bands 4-9 for the application of the RMIM. It is worth noting that these bands cover almost all of the spectral features for water constituents.

Please insert Fig. 5 here

Fig. 6 shows results of the comparison between the satellite-estimated and measured water constituent concentrations on Sept. 4, 2007, Aug. 7, 2008 (pink circles in Fig. 2b), and May 18, 2010 (pink circles in Fig. 2c) using the calibration dataset obtained on Aug. 07, 2008 (red crosses in Fig. 2b). It can be seen that the estimated values were in good agreement with the measured ones for validation datasets of August, 2008 and September, 2007, with an RMSE less than $10.2 \mathrm{mg} \mathrm{m}^{-3}$ for [Chl-a] estimation, less than $1.9 \mathrm{~g} \mathrm{~m}^{-3}$ for [TR] estimation, and less than $0.31 \mathrm{~m}^{-1}$ for [CDOM] estimation (Table 2). The average bias (MNB) and relative random uncertainty (NRMS) for these 
two periods also show lower values for estimating all water constituent concentrations. However, for the validation dataset of May, 2010, the satellite-estimated water constituent concentrations show noticeable biases from the measured values, with the largely increased RMSE and MNB of $27.6 \mathrm{mg}$ $\mathrm{m}^{-3}$ and $57.6 \%$ for [Chl-a], $9.5 \mathrm{~g} \mathrm{~m}^{-3}$ and $-49.2 \%$ for [TR], $0.54 \mathrm{~m}^{-1}$ and $81.6 \%$ for [CDOM], respectively. The NRMS for [Chl-a] and [CDOM] were also increased from $11.4 \%$ to $37.2 \%$, and from $23.1 \%$ to $43.1 \%$, but reduced from $29.7 \%$ to $10.5 \%$ for [TR], respectively (Table 2). From Fig. 6 and Table 2, it was noted that the RMIM yielded overestimations for [Chl-a] and [CDOM], and underestimation for [TR] for the validation dataset of May, 2010.

Please insert Fig. 6 here

Please insert Table 2 here

However, if we use the calibration dataset from May, 2010 (pink circles in Fig. 2c) instead of that from Aug., 2008, the opposite results were obtained (Fig. 7 and Table 3). For the validation dataset of May, 2010, the RMSE and MNB were largely reduced to $9.2 \mathrm{mg} \mathrm{m}^{-3}$ and 3.3\% for [Chl-a], $1.4 \mathrm{~g} \mathrm{~m}^{-3}$ and $1.1 \%$ for [TR], and $0.13 \mathrm{~m}^{-1}$ and $-3.2 \%$ for [CDOM], respectively. The NRMS for [Chl-a], [TR] and [CDOM] were also reduced to $16.1 \%, 8.0 \%$ and $16.6 \%$, respectively. In contrast, for the other two validation datasets, the RMSE and MNB were largely increased for both periods. Compared with the results shown in Fig. 6 and Table 2, the [Chl-a] and [CDOM] were systematically underestimated with MNB values ranging from $-18.3 \%$ to $-64.8 \%$; and the [TR] was overestimated with MNB values of $72.8 \%$ and $135.0 \%$, for validation datasets of August, 2008 and 
September, 2007, respectively (Table 3). These results indicate that an appropriate calibration dataset is needed for successful application of the RMIM.

Please insert Fig. 7 here

Please insert Table 3 here

\section{Discussion}

A relaxed matrix inversion method (RMIM) has been proposed for mapping the distributions of water constituent concentrations (i.e. [Chl-a], [TR], and [CDOM]) in case II waters. Unlike the original MIM, this method does not require the measurement of SIOPs, which are not generally included in routine observations of inland waters. The required inputs for the RMIM are several remote-sensing reflectance spectra and corresponding water constituent concentrations (at least 5 water samples). The former may be obtained from periodically acquired satellite data, and the latter may be obtained from routinely observed water quality data. Therefore, the RMIM can relax the limitation of the original MIM, and then can be applied to case II waters where no SIOPs are available.

Another merit of the RMIM is that it requires few water samples in the calibration process. According to Eq. 11, we can calculate the ESIOPs if more than five independent water samples were collected. In contrast, the Neural Network (NN) algorithms as well as empirical methods require a large number of water samples with enough dynamic range for calibration, because these methods are generally good interpolators and bad in extrapolations [37,38]. In addition, since architectures of the NN's are usually variable in different studies (e.g., [38-40]), it is more complicated to practically 
use the NN algorithms.

The performance of the RMIM was evaluated by using the simulation dataset and actual MERIS data. Based on the simulation dataset, a sensitivity analysis was carried out for testing the robustness of the RMIM, and also for the original MIM for comparison. Results indicate that the RMIM could effectively address the AC errors but suffered due to the spectrally uncorrelated noise resulting from satellite sensors compared with the original MIM. This may be explained by the different properties between the AC errors and the spectrally uncorrelated noises that were contained in the remote-sensing reflectance spectra. The AC errors can be recognized as 'systematic errors' resulting from imperfect aerosol correction; while the spectrally uncorrelated noise is a kind of unpredictable "random error" in the $R_{\mathrm{rs}}$ measurement. In the calibration process of the RMIM, all errors would be included into the ESIOPs. Since similar systematic errors (i.e., AC errors) were contained in all remote-sensing reflectance spectra, this kind of error could be compensated for in the inverse process of calibration (i.e. the process for retrieving the water constituent concentrations). However, the effect of random errors is completely unpredictable noise, and thus resulted in uncertainties in the RMIM. Fortunately, recently developed sensors, such as the MERIS and MODIS, provide high SNRs of bands for water monitoring [41, 42], thereby guaranteeing that the uncertainty in the RMIM is small (see error bars in Fig. 3). For the application of the MIM, there is no chance to compensate for systematic errors resulting from atmospheric correction since no calibration process is needed; thus, there was a dramatic increase of RMSE with increased AC errors (Fig. 3).

On the other hand, accurate measurements of water constituent concentrations for deriving the ESIOPs in the calibration process would be of great help in improving the performance of RMIM. 
This is because the measurement errors contained in the water constituent concentrations are propagated by means of ESIOPs, thereby reducing the estimation accuracy of the RMIM (Fig. 4). Unlike the remote-sensing reflectance spectra, there is no chance to compensate for the noise resulting from measurement errors of water constituent concentrations since these data were only used in the calibration process.

As with the empirical regression method or neural network (NN) method, the calibration process in the RMIM allows the ESIOPs to be used to gain information not only on the real SIOPs but also on the noise contained in the input datasets. Therefore, compared with the original MIM, the RMIM can reduce the effects of noise contained in the input datasets, and thus give higher estimation accuracy. However, the noises included in the ESIOPs will make their shapes and magnitudes different from the real SIOPs. Therefore, the use of RMIM to retrieve the SIOPs for phytoplankton, tripton and CDOM is still not appropriate. In the RMIM, the ESIOPs are used as intermediate variables for the purpose of retrieving water constituent concentrations.

Based on the results from the application of actual MERIS data in Lake Kasumigaura, it is clear that continually refining the ESIOPs to ensure they meet the actual conditions at the time being investigated is crucial for mapping more accurate water constituent concentrations. If the same calibration dataset was used for all seasons, the RMIM would show poor performance (Figs. 6 and 7). The similarity in the predicted accuracy for the datasets of August, 2008 and September, 2007 is due to the similarity in SIOPs in Lake Kasumigaura in the two periods. Figure 8 shows the derived ESIOPs in Lake Kasumigaura from three MERIS images. It can be seen that the ESIOPs of Sept. 04, 2007 are similar to those of Aug. 07, 2008 in shape and magnitude, while the ESIOPs of May 18, 
2010 are significantly different from those of the other two dates. This change is partially due to the fact that the SIOPs change seasonally according to the different dominant phytoplankton species. Fig. 9 shows the averaged proportion of the four main phytoplankton species in Lake Kasumigaura for each month during 1980-2008 [27]. It is noted that Cyanophyceae is the dominant species during the summer season (July, August, and September); while in May the dominant species is Bacillariphyceae. Accordingly, when using the ESIOPs derived from the dataset of Aug. 7, 2008, the RMIM yielded a much better estimation for the validation datasets of Aug., 2008 and Sept., 2007 than that of May 2010; and when using the ESIOPs derived from the dataset of May 18, 2010, the accuracy of the RMIM for validation dataset of May, 2010 was significantly higher than those of Aug., 2008 and Sept., 2007.

The data accumulated for Lake Kasumigaura allow us to refine the ESIOPs to correspond to the actual conditions of the time being investigated rather than introducing error by using the same values for all conditions, and thus can provide a more accurate spatial distribution map for regular water quality monitoring in the Lake.

Please insert Fig. 8 here

Please insert Fig. 9 here

\section{Conclusion}

In this study, we presented the RMIM, a relaxed matrix inversion method for mapping water constituent concentrations in case II waters. The most significant characteristic of he RMIM is that 
its required inputs can all be obtained from periodical satellite data and routine field observations. In this respect, the RMIM can extend the applicability of linear matrix inversion theory to situations in which appropriate SIOPs for the study area are unavailable, particularly for post-session studies (e.g. 1980s-2000s for Lake Kasumigaura). The performance of the proposed method was evaluated through sensitivity analysis based on simulation experiments and three MERIS images. The results showed that the RMIM could retrieve an acceptable estimation of water constituent concentrations in our study area (Lake Kasumigaura).

Acknowledgement: This research was supported in part by National Natural Science Foundation of China (Grant No. 40871162), by the Grants-in-Aid for Scientific Research of MEXT from Japan (No. 2051003), the Global Environment Research Fund (M-10) of the Ministry of the Environment, Japan, and also by Japan Society for the Promotion of Science. The authors would like to acknowledge Dr. L. Guanter, who developed the SCAPE-M processor and performed atmospheric correction on the MEIRS images used in this study. The authors would also like to thank the two anonymous reviewers for the valuable comments on the manuscript.

\section{References:}

[1] W. Ayres, A. Busia, A. Dinar, R. Hirji, S. Lintner, A. McCalla, and R. Robelus, Integrated lake and reservoir management: World band approach and experience vol. 358. Washington, DC.: World Bank, 1996.

[2] A. Morel and L. Prieur, "Analysis of variations in ocean color," Limnol. Oceanogr., vol. 22, no. 
4, pp. 709-722, Aug. 1977.

[3] IOCCG, "Remote Sensing of Ocean Colour in Coastal, and Other Optically-Complex Waters," IOCCG, Dartmouth, Canada No. 3, 2000.

[4] W. J. Moses, A. A. Gitelson, S. Berdnikov, and V. Povazhnyy, "Satellite estimation of chlorophyll-a concentration using the red and NIR bands of MERIS-The Azov sea case study," IEEE Geosci. Remote Sens. Lett., vol. 6, no. 4, pp. 845-849, Ocrt. 2009.

[5] B. Matsushita and T. Fukushima, "Methods for retrieving hydrologically significant eurface parameters from remote sensing: a review for applications to East Asia region," Hydrological Processes, vol. 23, no. 4, pp. 524-533, Feb. 2009.

[6] P. Ammenberg, P. Flink, T. Lindell, D. Pierson, and N. Strombeck, "Bio-optical modelling combined with remote sensing to assess water quality," Int. J. Remote Sens., vol. 23, no. 8, pp. 1621-1638, Apr. 2002.

[7] D. G. Goodin, L. Han, R. N. Fraser, D. C. Rundquist, W. A. Stebbins, and J. F. Schalles, "Analysis of suspended solids in water using remotely sensed high resolution derivative spectra," Photogrammetric Engineering and Remote Sensing, vol. 59, no. 4, pp. 505-510, Apr. 1993.

[8] L. Han, D. C. Rundquist, L. L. Liu, R. N. Fraser, and J. F. Schalles, "The spectral responses of algal chlorophyll in water with varying levels of suspended sediment," Int. J. Remote Sens., vol. 15, no. 18, pp. 3707-3718, Dec. 1994.

[9] A. A. Gitelson, G. Dall'Olmo, W. Moses, D. C. Rundquist, T. Barrow, T. R. Fisher, D. Gurlin, and J. Holz, "A simple semi-analytical model for remote estimation of chlorophyll-a in turbid waters: Validation," Remote Sens. Environ., vol. 112, no. 9, pp. 3582-3593, Sep. 2008.

[10] F. E. Hoge and P. E. Lyon, "Satellite retrieval of inherent optical properties by linear matrix inversion of oceanic radiance models: An analysis of model and radiance measurement errors " $J$. Geophys. Res., vol. 101, no. C7, pp. 16631-16648, Jul. 1996.

[11] H. J. Hoogenboom, A. G. Dekker, and J. F. De Haan, "Retrieval of chlorophyll and suspended matter in inland waters from CASI data by matrix inversion," Can. J. Remote Sen., vol. 24, pp. 144-152, 1998.

[12] A. N. Tyler, E. Svab, T. Preston, M. Présing, and W. A. Kovács, " Remote sensing of the water quality of shallow lakes: A mixture modeling approach to quantifying phytoplankton in water characterized by high-suspended sediment," Int. J. Remote Sens., vol. 27, no. 8, pp. 1521-1537, Apr. 2006.

[13] Y. Oyama, B. Matsushita, T. Fukushima, T. Nagai, and A. Imai, "A new algorithm for estimating chlorophyll-a concentration from multi-spectral satellite data in Case II waters: A simulation based on a controlled laboratory experiment," Int. J. Remote Sens., vol. 28, no. 7 pp. 1437-1453, Jan. 2007.

[14] Y. Oyama, B. Matsushita, T. Fukushima, K. Matsushige, and A. Imai, "Application of spectral decomposition algorithm for mapping water quality in a turbid lake (Lake Kasumigaura, Japan) from Landsat TM data," ISPRS Journal of Photogrammetry \& Remote Sensing, vol. 64, no. 1, pp. 73-85, Jan. 2009.

[15] F. Santini, L. Alberotanza, R. M. Cavalli, and S. Pignatti, "A two-step optimization procedure for assessing water constituent concentrations by hyperspectral remote sensing techniques: An application to the highly turbid Venice lagoon waters, " Remote Sens. Environ., vol. 14, no. 4, pp. 
887-898, Apr. 2010.

[16] H. J. Van Der Woerd and R. Pasterkamp, "HYDROPT: A fast and flexible method to retrieve chlorophyll-a from multispectral satellite observations of optically complex coastal waters," Remote Sens. Environ., vol. 112, no. 4, pp. 1795-1807, Apr. 2008.

[17] V. E. Brando and A. G. Dekker, "Satellite hyperspectral remote sensing for estimating estuarine and coastal water quality," IEEE Trans. Geosci. Remote Sens., vol. 41, no. 6, pp. 1378-1387, Jun. 2003.

[18] C. Giardino, V. E. Brando, A. G. Dekker, N. Strömbeck, and G. Candiani, "Assessment of water quality in Lake Garda (Italy) using Hyperion," Remote Sens. Environ., vol. 109, no. 2, pp. 183-195, Jul. 2007.

[19] D. Odermatt, C. Giardino, and T. Heege, "Chlorophyll retrieval with MERIS Case-2-Regional in perialpine lakes," Remote Sens. Environ., vol. 114, no. 3, p. 607, Mar. 2010.

[20] G. Campbell and S. Phinn, "An assessment of the accuracy and precision of water quality parameters retrieved with the Matrix Inversion Method," Limnol. Oceanogr.: Methods, vol. 8, pp. 16-29, Jan. 2010.

[21] H. R. Gordon, O. B. Brown, R. H. Evans, J. W. Brown, R. C. Smith, K. S. Baker, and D. K. Clark, "A semianalytic radiance model of ocean color," J. Geophys. Res., vol. 93, no. D9, pp. 10909-10924, Sep.1988.

[22] R. W. Austin, "Gulf of Mexico, ocean-colour surface-truth measurements," Bound.-Layer Meteorol., vol. 18, no. 3, pp. 269-285, May 1980.

[23] G. M. Hale and M. R. Querry, "Optical constants of water in the $200 \mathrm{~nm}$ to 200 micrometer wavelength region," Appl. Opt., vol. 12, no. 3, pp. 555-563, Mar. 1973.

[24] R. M. Pope and E. S. Fry, "Absorption spectrum (380-700 nm) of pure water. II. Integrating cavity measurements," Appl. Opt., vol. 36, no. 33, pp. 8710-8723, Nov. 1997.

[25] A. Morel, "Optical properties of pure sea water," in Optical Aspects of Oceanography London, U.K.: Academic, 1974.

[26] C. D. Mobley, Light and Water: Radiative Transfer in Natural Waters. San Diego: Academic Press, 1994.

[27] CGER, "Lake Kasumigaura Database," National Institute for Environmental Studies, Japan, 2010.

[28] K. G. Ruddick, F. Ovidio, and M. Rijkeboer, "Atmospheric Correction of SeaWiFS Imagery for Turbid Coastal and Inland Waters," Appl. Opt., vol. 39, no. 6, pp. 897-912, Feb. 2000.

[29] SCOR-UNESCO, "Determination of photosynthetic pigment in seawater. Monographs on oceanographic methodology," Paris, France 1966.

[30] H. J. Gons, T. Burger-Wiersma, J. H. Otten, and M. Rijkeboer, "Coupling of phytoplankton and detritus in a shallow, eutrophic lake (Lake Loosdrecht, The Netherlands)," Hydrobiologia, vol. 233, no. 1-3, pp. 51-59, May 1992.

[31] L. Guanter, A. Ruiz-Verdu, D. Odermatt, C. FGiardino, S. Simis, V. Estelles, T. Heege, J. A. Dominguez-Gomez, and J. Moreno, "Atmospheric correction of ENVISAT/MERIS data over inland waters: Validation for European lakes," Remote Sens. Environ., vol. 114, no. 3, pp. 467-480, Mar. 2010.

[32] J. L. Mueller, C. Davis, R. Arnone, R. Frouin, K. Carder, and Z. P. Lee, "Above-water radiance 
and remote sensing reflectance measurements and analysis protocols," in Ocean Optics protocols for satellite ocean color sensor validation Revision 2 Greenbelt, Maryland: National Aeronautical and Space Administration, 2000, pp. 98-107.

[33] Z. Lee, K. L. Carder, C. D. Mobley, R. G. Steward, and J. S. Patch, "Hyperspectral remote sensing for shallow waters: 2. Deriving bottom depths and water properties by optimization," Appl. Opt., vol. 38, no. 18, pp. 3831-3843, Jun.1999.

[34] Z. P. Lee and K. L. Carder, "Particle phase function and remote-sensing reflectance model: a revisit," in Ocean Color Research Team Meeting San Diego, California, 2001.

[35] J. T. O. Kirk, Light and Photosynthesis in Aquatic Ecosystem. Cambridge, U.K.: Cambridge Univ. Press, 1994.

[36] H. J. Gons, "Optical teledetection of chlorophyll a in turbid inland waters," Environ. Sci. Technol., vol. 33, no. 7, pp. 1127-1132, Apr. 1999.

[37] C. L Chiang, Statistical methods of analysis. Singapore: World Scientific, 2003.

[38] L. Vilas, E. Spyrakos, and J. Palenzuela, "Neural network estimation of chlorophyll a from MERIS full resolution data for the coastal waters of Galician rias (NW Spain) " Remote Sens. Environ., vol. 115, no. 2, pp. 524-535, Feb. 2011.

[39] R. Doerffer and H. Schiller, "The MERIS Case 2 water algorithm " Int. J. Remote Sens., vol. 28, no. 3-4, pp. 517-535, Feb. 2007.

[40] Y. Zhang, J. Pulliainen, S. Koponen, and M. Hallikainen, "Application of an empirical neural network to surface water quality estimation in the Gulf of Finland using combined optical data and microwave data " Remote Sens. Environ., vol. 81, no. 2-3, pp. 327-336, Aug. 2002.

[41] M. Wang, "Remote sensing of the ocean contributions from ultraviolet to near-infrared using the shortwave infrared bands: simulations," Appl. Opt., vol. 46, no. 9, pp. 1535-1546, Mar. 2007.

[42] J. Fischer and R. Bennartz, "ATBD retrieval of total water vapour content from MERIS measurements," Freie Universität Berlin 1997.

\section{List of Tables}

Table 1 Parameters for Hydrolight simulation.

\begin{tabular}{ll}
\hline Parameters & Values or Ranges \\
\hline Solar zenith angle & $30^{\circ}$ \\
Sensor viewing direction & Nadir \\
Wind speed (m/s) & 5 \\
Wavelength (nm) & $460-740$, every $10 \mathrm{~nm}$ \\
{$[\mathrm{Chl}-\mathrm{a}]\left(\mathrm{mg} \mathrm{m}^{-3}\right)$} & Random values in the range of $0-20$ \\
{$[\mathrm{TR}]\left(\mathrm{g} \mathrm{m}^{-3}\right)$} & Random values in the range of $0-25$ \\
{$[\mathrm{CDOM}]\left(\mathrm{m}^{-1}\right)$} & Random values in the range of $0-0.5$ \\
Specific apsorption and backscattering coefficients & Cited from Brando and Dekker [17] \\
Inelastic scattering & Without \\
\hline
\end{tabular}

Table 2 Comparison of estimation accuracy for validation datasets of three dates (Sept. 4, 2007; Aug. 7, 2008; May 18, 2010) using the calibration dataset of Aug. 7, 2008. 


\begin{tabular}{llccc}
\hline & & [Chl-a] & [TR] & [CDOM] \\
\hline Sept. 4, 2007 & RMSE $^{*}$ & 10.116 & 1.889 & 0.302 \\
& MNB (\%) & -4.487 & 1.327 & 2.860 \\
& NRMS (\%) & 11.365 & 29.670 & 23.069 \\
Aug.7, 2008 & RMSE $^{*}$ & 7.541 & 1.530 & 0.143 \\
& MNB (\%) & 3.184 & -5.746 & -11.143 \\
& NRMS (\%) & 10.536 & 15.310 & 4.734 \\
May 18, 2010 & RMSE & 27.658 & 9.472 & 0.542 \\
& MNB (\%) & 57.575 & -49.249 & 81.649 \\
& NRMS (\%) & 37.177 & 10.499 & 43.093 \\
\hline
\end{tabular}

*RMSE is with the unit of $\mathrm{mg} \mathrm{m}^{-3}, \mathrm{~g} \mathrm{~m}^{-3}$, and $\mathrm{m}^{-1}$ for [Chl-a], [TR], and [CDOM], respectively.

Table 3 Comparison of estimation accuracy for validation datasets of three dates (Sept. 4, 2007; Aug. 7, 2008; May 18, 2010) using the calibration dataset of May 18, 2010.

\begin{tabular}{llccc}
\hline & & [Chl-a] & [TR] & [CDOM] \\
\hline Sept. 4, 2007 & RMSE $^{*}$ & 27.906 & 11.601 & 0.455 \\
& MNB (\%) & -30.849 & 135.037 & -18.127 \\
& NRMS (\%) & 6.728 & 54.625 & 21.302 \\
Aug.7, 2008 & RMSE $^{*}$ & 23.501 & 6.552 & 0.776 \\
& MNB (\%) & -29.756 & 72.823 & -64.705 \\
& NRMS (\%) & 17.202 & 38.238 & 7.391 \\
May 18, 2010 & RMSE $^{*}$ & 9.196 & 1.401 & 0.126 \\
& MNB (\%) & 3.331 & 1.118 & -3.175 \\
& NRMS (\%) & 16.069 & 8.005 & 16.559 \\
\hline
\end{tabular}

* RMSE is with the unit of $\mathrm{mg} \mathrm{m}^{-3}, \mathrm{~g} \mathrm{~m}^{-3}$, and $\mathrm{m}^{-1}$ for [Chl-a], [TR], and [CDOM], respectively.

\section{List of Figures}

Fig. 1. Simulated remote-sensing reflectance just above the water by Hydrolight simulation for (a) calculating the ESIOPs and (b) validating performance of the algorithms.

Fig. 2. MERIS images and sampling stations of Lake Kasumigaura, Japan on (a) September 4, 2007, (b) August 7, 2008, and (c) May 18, 2010.

Fig. 3. Plots of the average RMSE of retrieval of (a) chlorophyll-a concentration, (b) tripton concentration, and (c) absorption of CDOM at $440 \mathrm{~nm}$ against the noise level in $R_{\mathrm{rs}}$ for MIM and RMIM. Error bars denote the variation of RMSE caused by Gaussian noise in spectra.

Fig. 4. Plots of the average RMSE of retrieval of (a) chlorophyll-a concentration, (b) tripton concentration, and (c) absorption of CDOM at $440 \mathrm{~nm}$ against the noise level in constituent 
concentrations of calibration dataset for the RMIM, and the noise level of SIOPs for the original MIM. Error bars denote the variation of RMSE caused by Gaussian noise in the spectra.

Fig. 5. Comparison between in situ collected and atmospherically corrected remote-sensing reflectance spectra in Lake Kasumigaura on August 7, 2008.

Fig. 6. Comparison of measured and estimated (a) chlorophyll-a concentration, (b) tripton concentration, and (c) absorption of CDOM at $440 \mathrm{~nm}$ from MERIS data using the calibration dataset of August 7, 2008.

Fig. 7. Comparison of measured and estimated (a) chlorophyll-a concentration, (b) tripton concentration, and (c) absorption of CDOM at $440 \mathrm{~nm}$ from MERIS data using the calibration dataset of May 18, 2010.

Fig. 8. The Estimated SIOPs (ESIOPs, i.e., ${a_{\mathrm{ph}}}^{*}, a_{\mathrm{tr}}{ }^{*}, a_{\mathrm{CDOM}}{ }^{*}, b_{\mathrm{b}, \mathrm{ph}}{ }^{*}$, and $b_{\mathrm{b}, \mathrm{rr}}{ }^{*}$ ) from the MERIS data in Lake Kausmigaura on Sept. 4, 2007, Aug. 7, 2008, and May 18, 2010, respectively.

Fig. 9. Monthly averaged proportion of four main phytoplankton species in Lake Kasumigaura from 1980 to 2008.

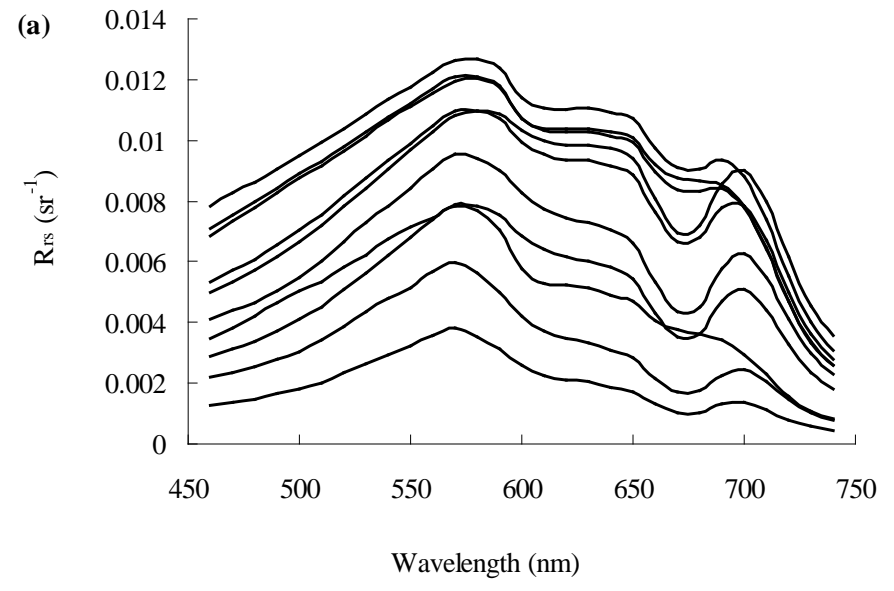




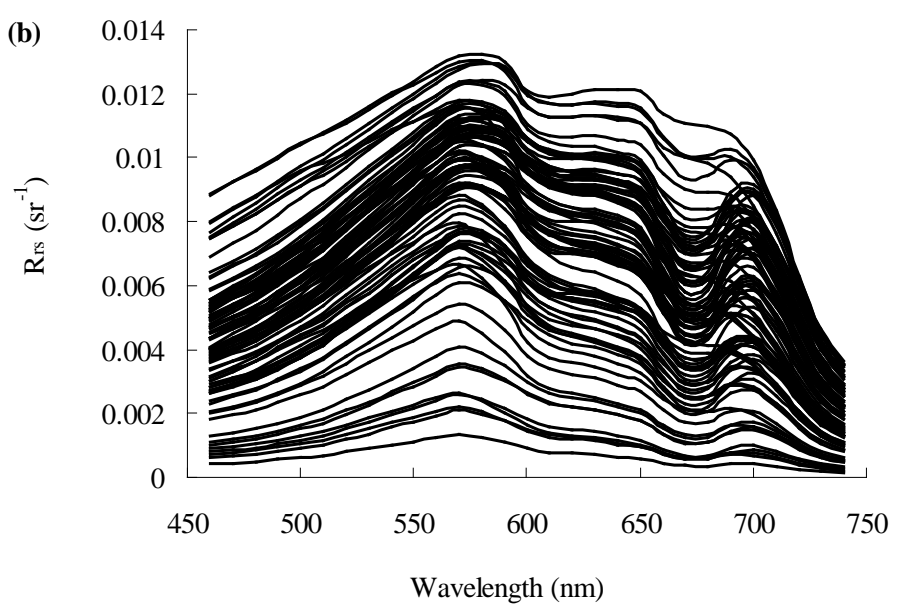

Fig. 1
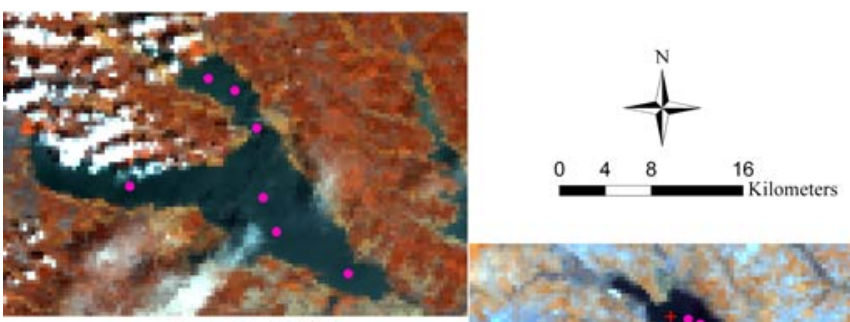

(a) September 4,2007
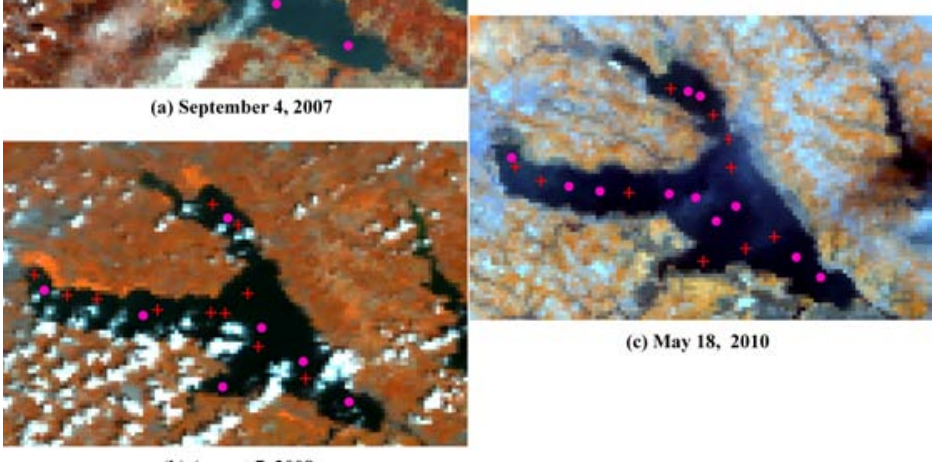

(c) May 18, 2010

(b) August 7, 2008

Fig. 2 
(a)

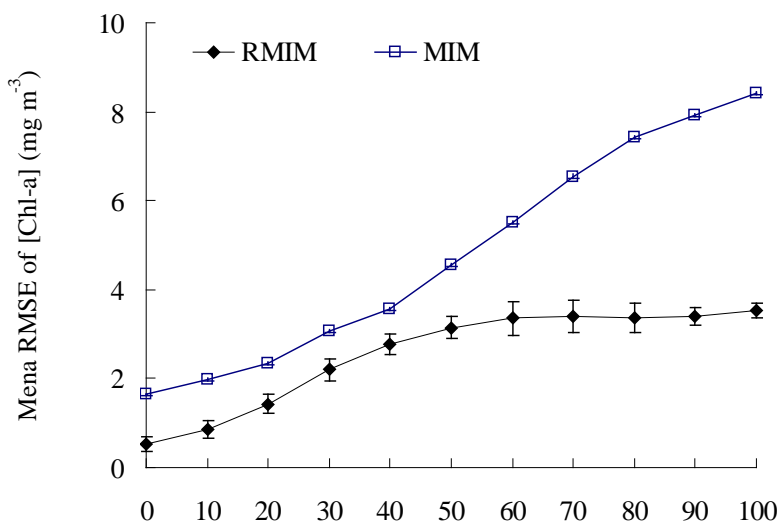

Percentage of AC errors (\%)

(b)

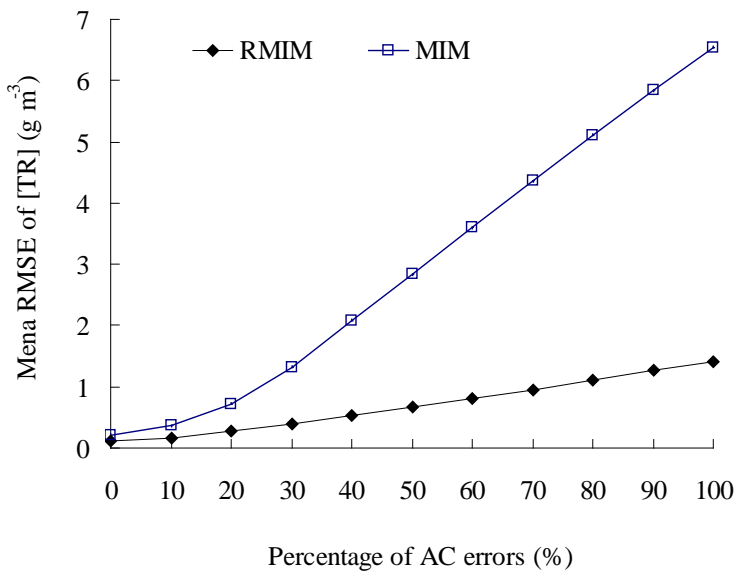

(c)

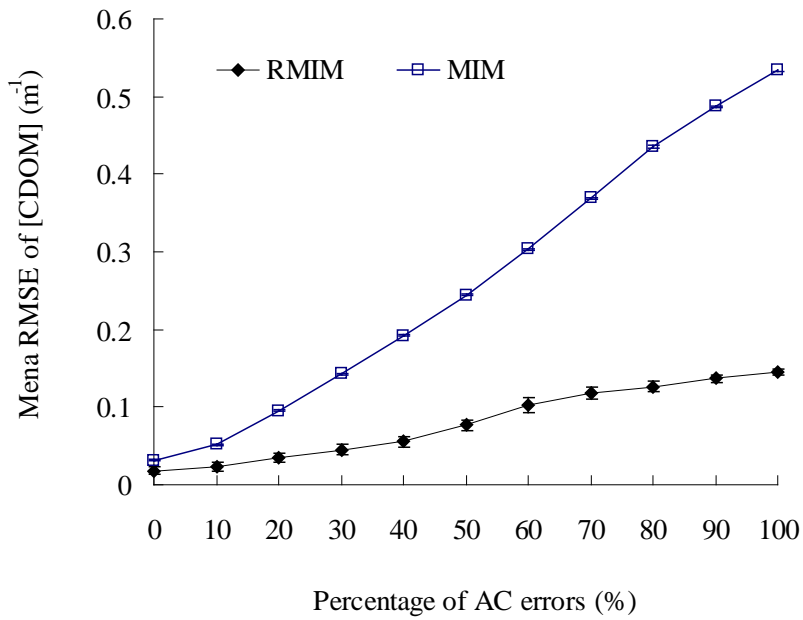

Fig. 3 
(a)

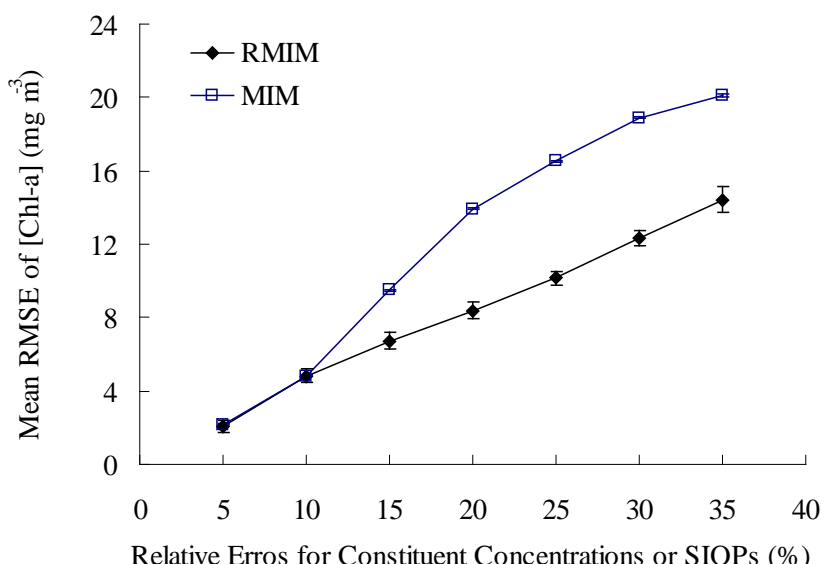

(b)

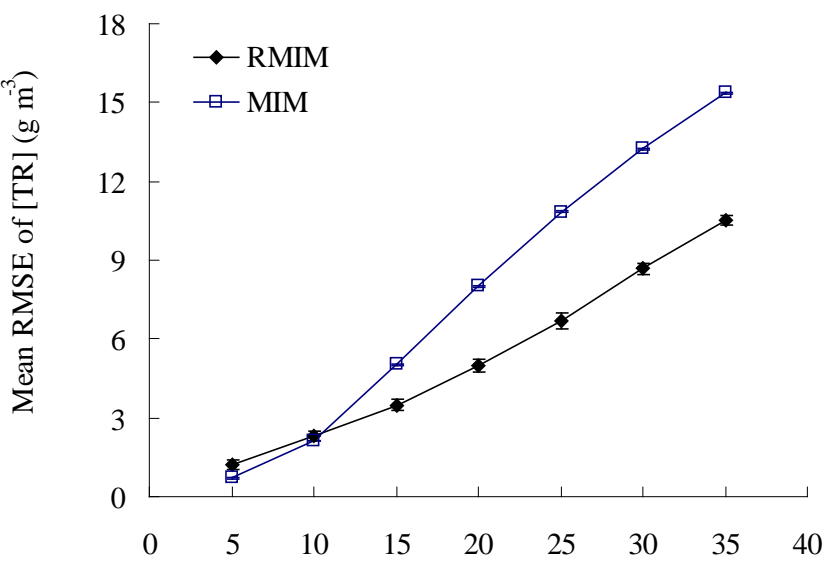

Relative Erros for Constituent Concentrations or SIOPs (\%)

(c)

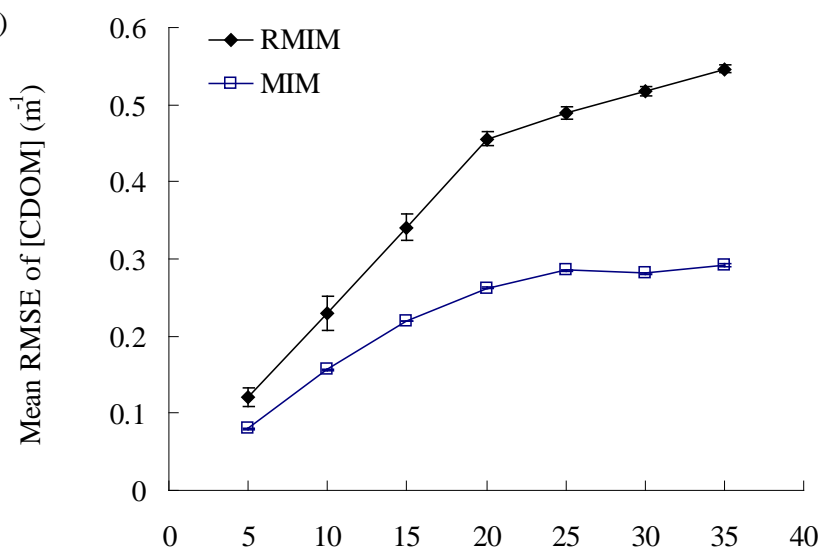

Relative Erros for Constituent Concentrations or SIOPs (\%)

Fig. 4 

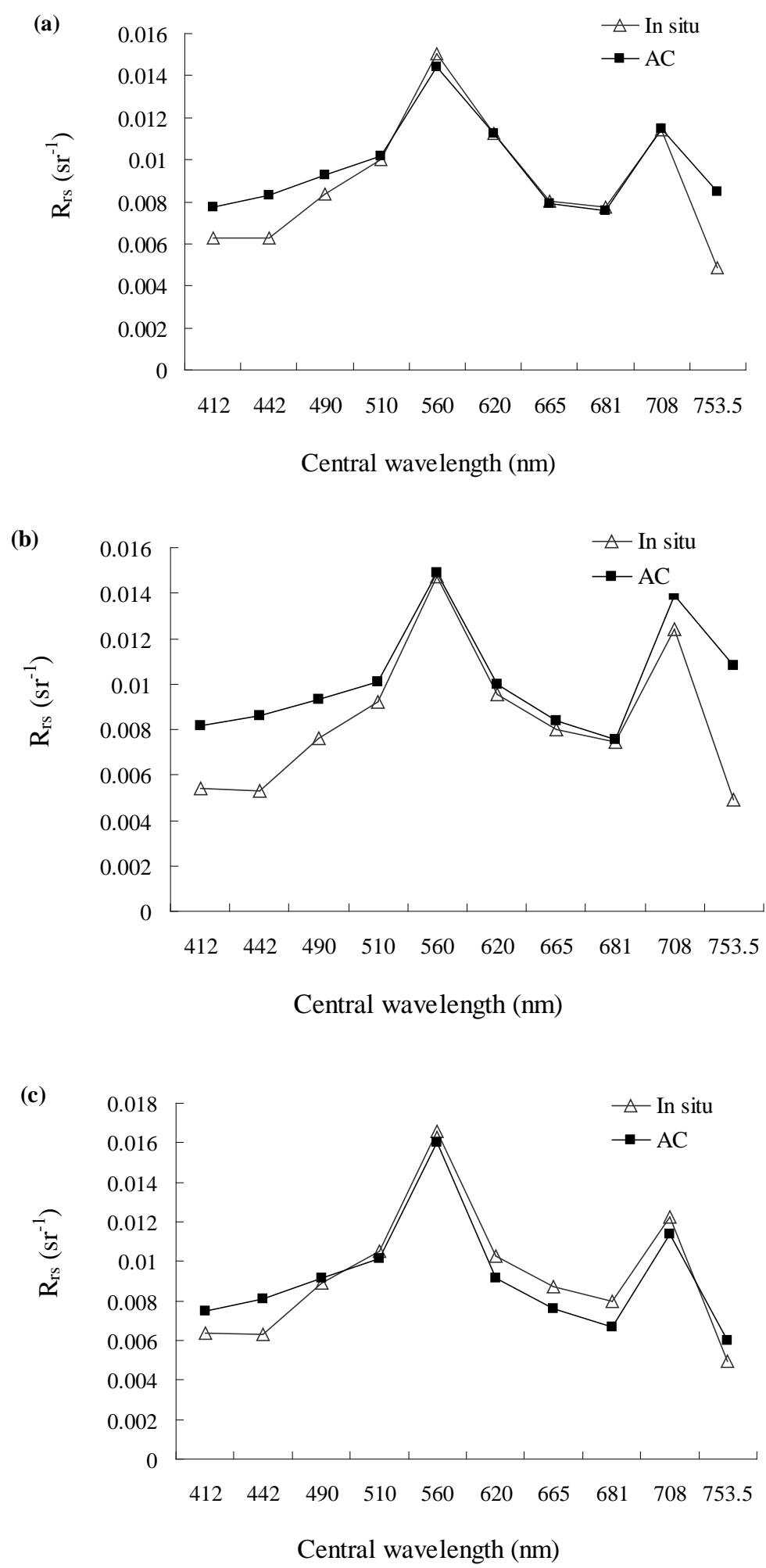


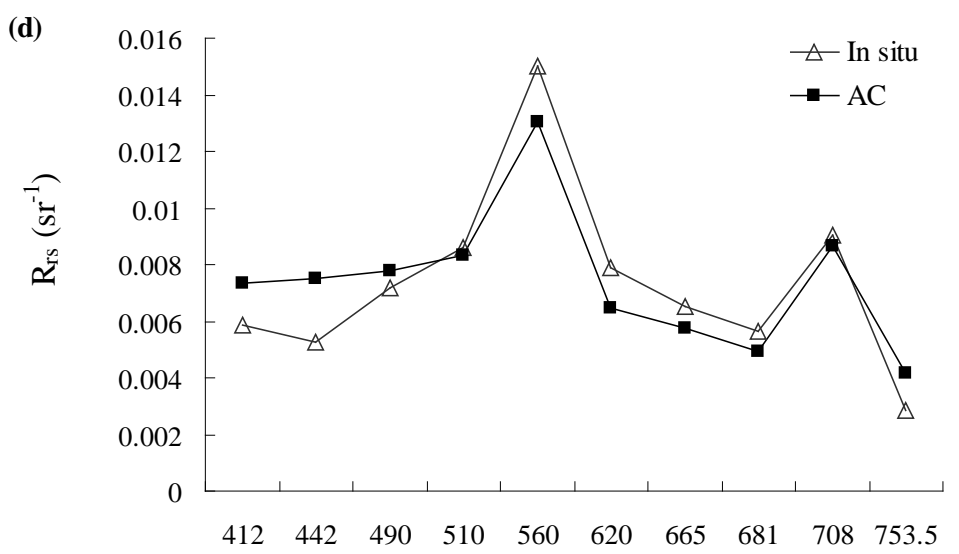

Central wavelength (nm)

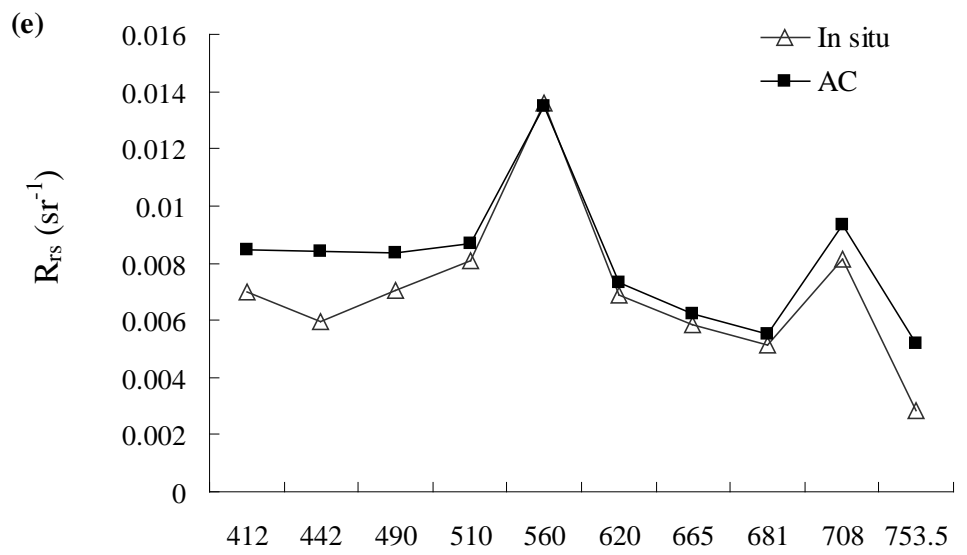

Central wavelength (nm)

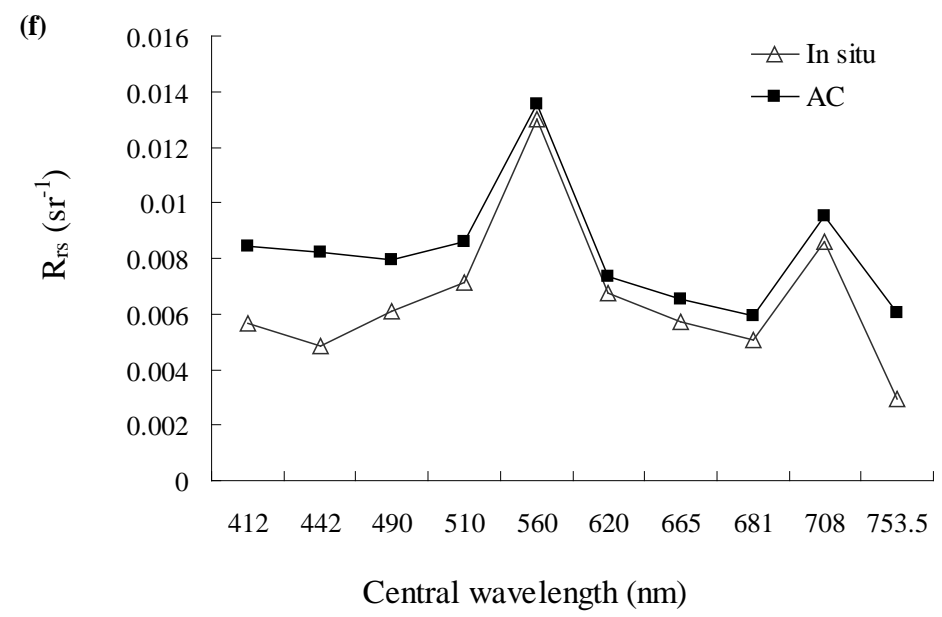




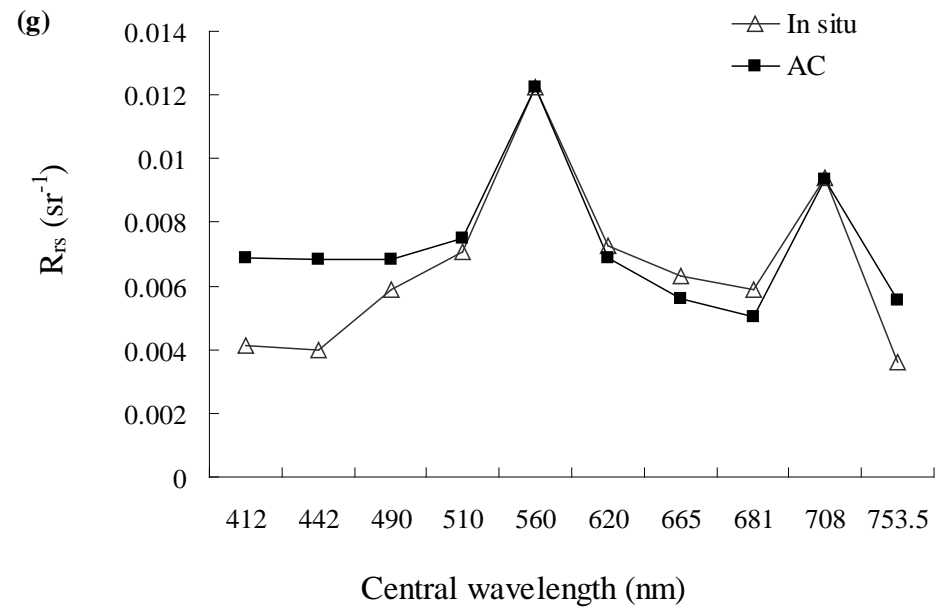

Fig. 5

(a)

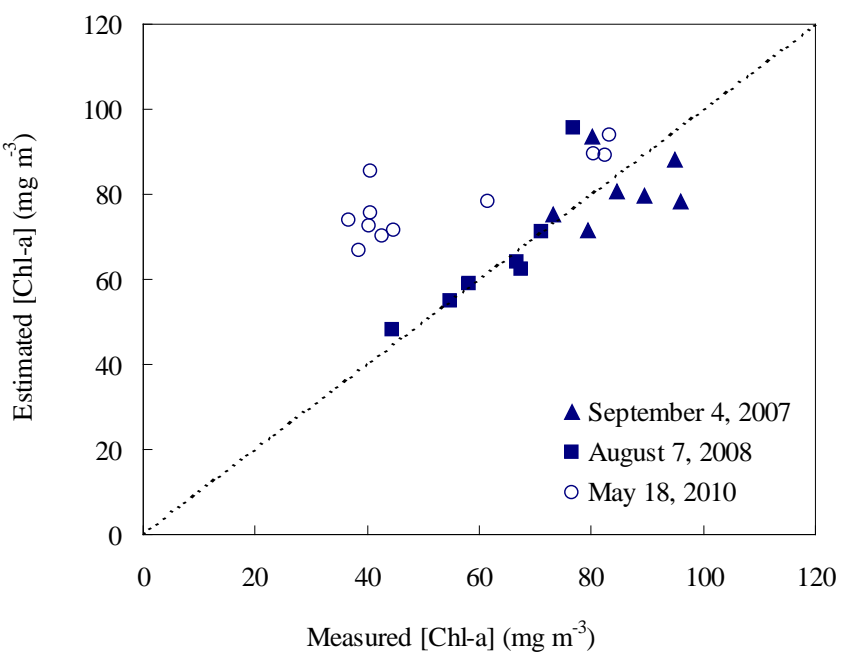

(b)

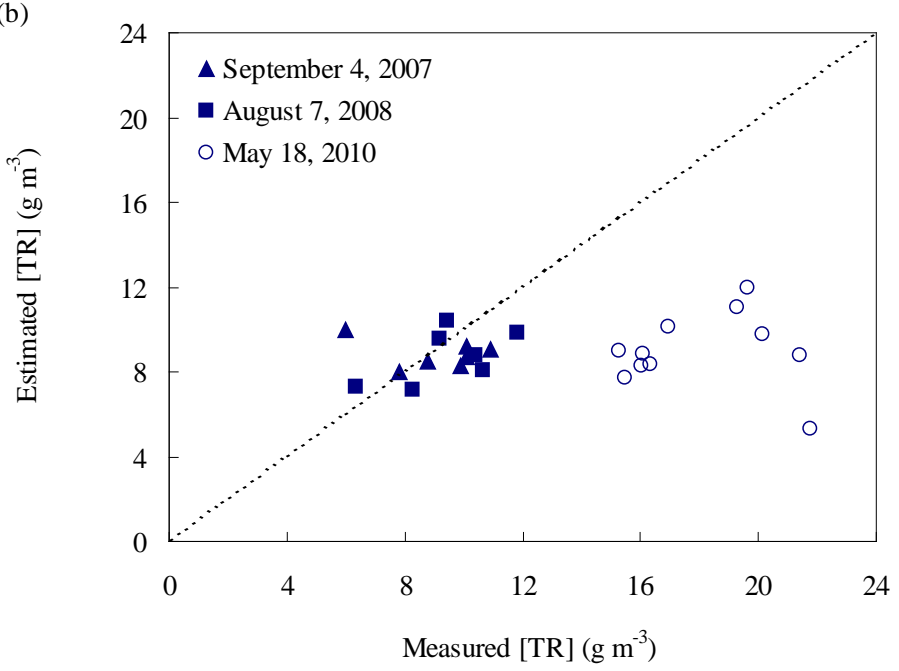




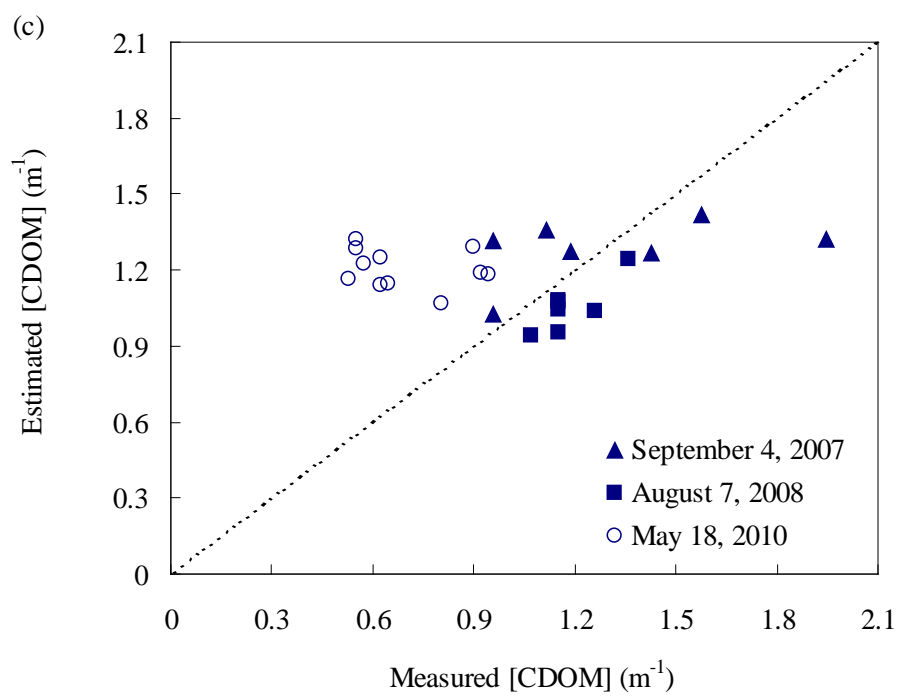

Fig. 6

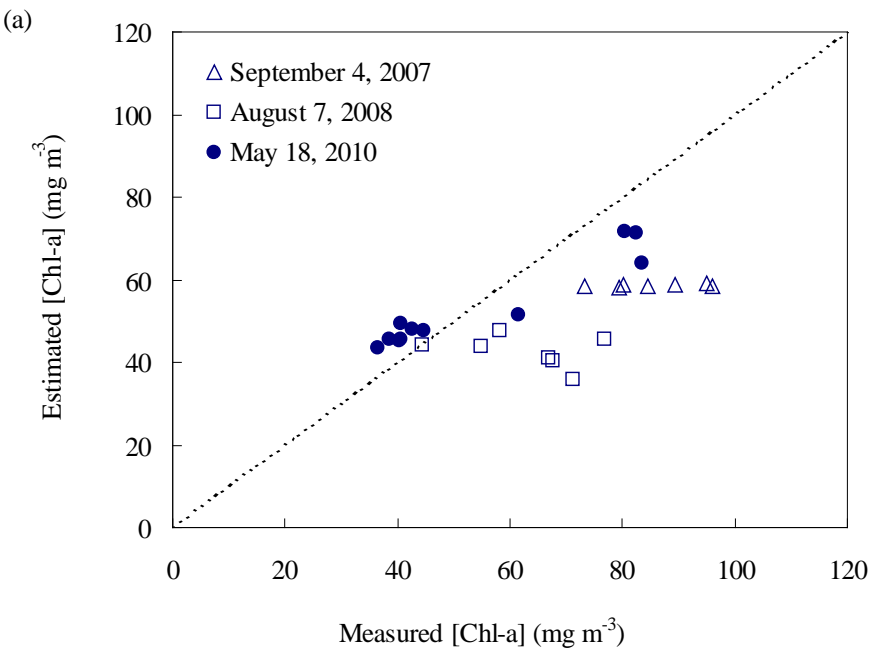



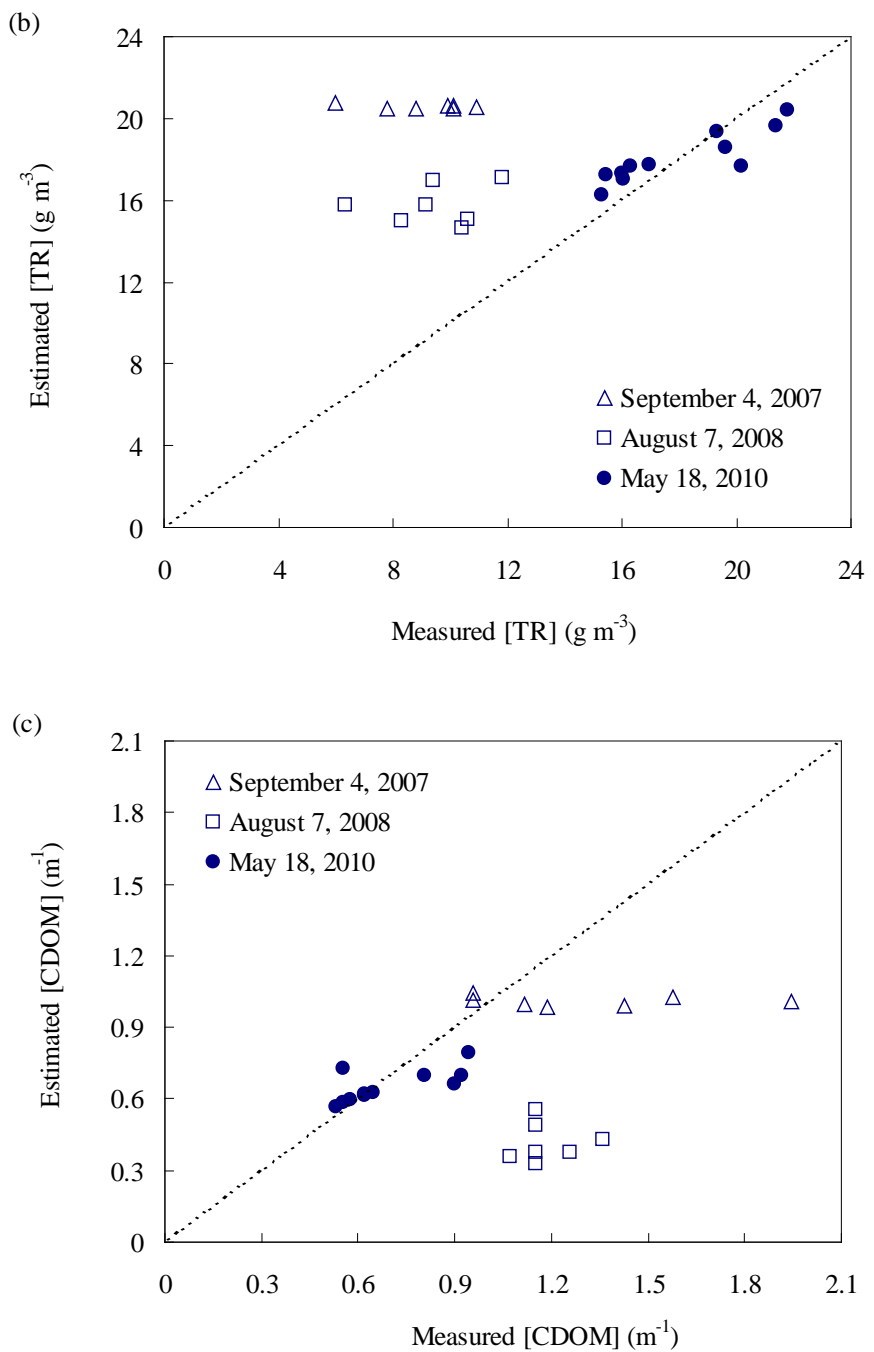

Fig. 7 

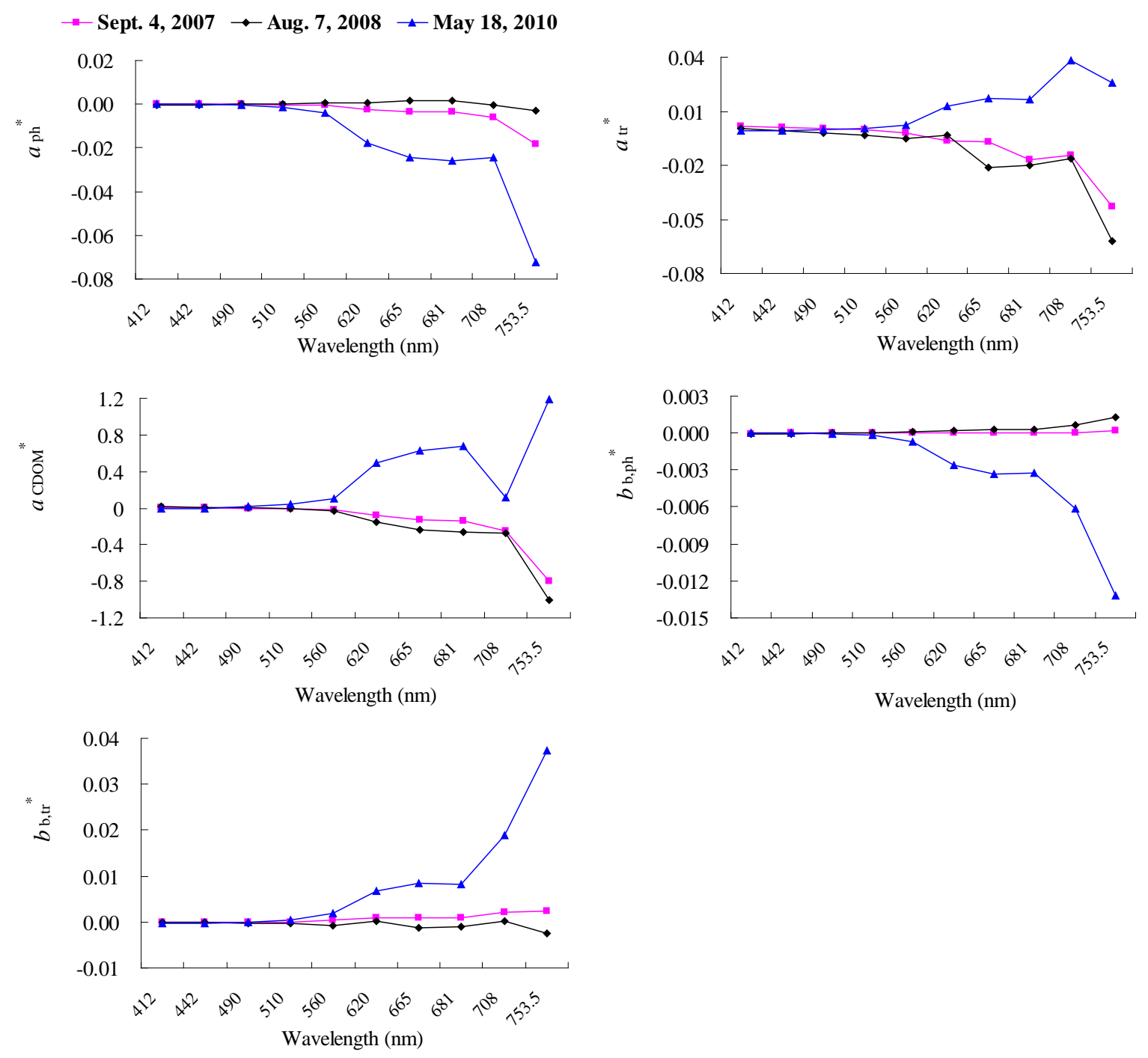

Fig. 8 


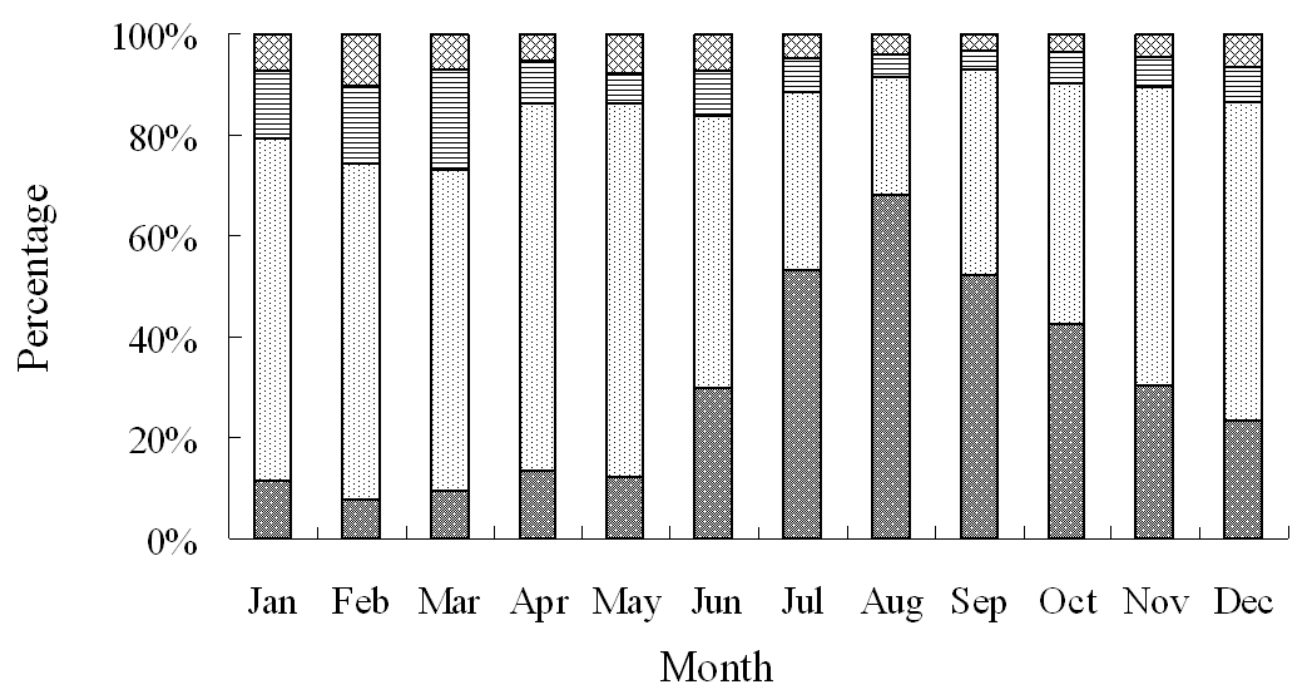

$\square$ Cyanophyceae Bacillariophyceae 目 Cryptophyceae $\otimes$ Chlorophyceae

Fig. 9 